\title{
Treatment Patterns in Patients with Locally Advanced or Metastatic Non-Small-Cell Lung Cancer Treated with Epidermal Growth Factor Receptor-Tyrosine Kinase Inhibitors: Analysis of US Insurance Claims Databases
}

\author{
Ross A. Soo ${ }^{1}$ (1) Takashi Seto $^{2} \cdot$ Jhanelle E. Gray $^{3} \cdot$ Ellen Thiel $^{4} \cdot$ Aliki Taylor $^{5} \cdot$ William Sawyer $^{6} \cdot$ Parisa Karimi $^{7}$. \\ Elizabeth Marchlewicz ${ }^{4} \cdot$ Matthew Brouillette $^{4}$
}

Accepted: 28 July 2021 / Published online: 12 September 2021

(c) The Author(s) 2021

\begin{abstract}
Background Most patients with epidermal growth factor receptor mutation-positive (EGFRm) non-small-cell lung cancer (NSCLC) acquire resistance to first-line (1L) first- or second-generation (1G/2G) EGFR-TKIs; therefore, it is important to optimize $1 \mathrm{~L}$ treatment to improve patient outcomes.

Objective To retrospectively examine treatment patterns in locally advanced/metastatic NSCLC using MarketScan ${ }^{\circledR}$ Commercial and Medicare Supplemental Databases (all US census regions).

Patients and methods Adults with a lung cancer diagnosis code between 1 January 2015-31 March 2018 were analyzed from diagnosis (index) through a variable-length follow-up. Patients had $\geq 1$ pharmacy claim for $1 \mathrm{G} / 2 \mathrm{G}$ EGFR-TKIs on or within 60 days post-index. Data were stratified by presence or absence of central nervous system (CNS) metastases (30 days pre-index through study end).

Results 578 patients were included (median age 63 years, $64 \%$ female). Median follow-up was 13.5 months. The most frequently prescribed 1L EGFR-TKI was erlotinib (414/578, 72\%). Median time to $1 \mathrm{~L}$ treatment discontinuation was 8.2 (95\% confidence interval (CI) 6.9,9.0) months in patients diagnosed with CNS metastases at any time, and 7.7 (95\% CI 6.9, 8.9) months in patients without CNS metastases. 270/578 patients (47\%) discontinued 1L EGFR-TKIs; 209/270 (77\%) initiated second-line (2L) therapy, most frequently osimertinib (96/209, 46\%).

Conclusions In an analysis of US claims data, nearly half of patients discontinued 1L EGFR-TKIs, and 46\% who initiated $2 \mathrm{~L}$ received osimertinib. As nearly a quarter of patients who discontinued $1 \mathrm{~L}$ EGFR-TKIs did not receive $2 \mathrm{~L}$ treatment, this study highlights the need for optimal 1L treatment in EGFRm locally advanced/metastatic NSCLC.
\end{abstract}

\section{Key Points}

Median time to first-line treatment discontinuation was 8.2 months in patients with CNS metastases and 7.7 months in patients without CNS metastases.

209 of the 270 patients who discontinued first-line treatment initiated second-line NSCLC therapy and of those, $46 \%$ initiated osimertinib at second line.

Ross A. Soo

ross_soo@nuhs.edu.sg

Extended author information available on the last page of the article

\section{Introduction}

Non-small-cell lung cancer (NSCLC) accounts for approximately $80-90 \%$ of all lung cancers [1]. Epidermal growth factor receptor (EGFR) mutations are observed in approximately $10-20 \%$ and $30-50 \%$ of patients with NSCLC in non-Asian and Asian populations, respectively [2,3].

Central nervous system (CNS) metastases are observed frequently in patients with NSCLC, and are associated with a poor prognosis and high economic burden [4, 5]. Moreover, CNS metastases have been found to be more common in patients with EGFR mutation-positive (EGFRm) NSCLC, developing in approximately $70 \%$ of patients, compared with $38 \%$ among patients with negative EGFR mutation status [6]. 
EGFR-tyrosine kinase inhibitors (EGFR-TKIs) are the recommended first-line (1L) treatment in patients with EGFRm advanced/metastatic NSCLC [1, 7]. Despite initial responses, most patients treated in the $1 \mathrm{~L}$ with a first- or second-generation (1G/2G) EGFR-TKI develop resistance after a median period of 8-16 months [8, 9], with the EGFR T790M resistance mutation observed in approximately $50 \%$ of patients [10].

Osimertinib, a third-generation, irreversible, EGFRTKI, potently and selectively inhibits both EGFR-TKIsensitizing and T790M resistance mutations and has demonstrated efficacy in NSCLC CNS metastases [11-15]. Osimertinib initially received US Food and Drug Administration (FDA) accelerated approval in November 2015 for patients with T790M mutation-positive NSCLC and disease progression on or after EGFR-TKI treatment, and was granted full approval in this setting in March 2017 based on the confirmatory phase III AURA3 study [12]. Based on the phase III FLAURA study, osimertinib was approved as $1 \mathrm{~L}$ treatment in patients with EGFRm (Ex19del or L858R) metastatic NSCLC in April 2018 (median progression-free survival (PFS) 18.9 months with osimertinib vs. 10.2 months with comparator EGFR-TKI; hazard ratio (HR) 0.46 ; median overall survival (OS) 38.6 months with osimertinib vs. 31.8 months with comparator EGFR-TKI; HR 0.80) $[13,16]$. Given the evolving therapeutic landscape for EGFRm NSCLC, there remains a need to define an optimal treatment strategy. Real-world data can support this through an improved understanding of current treatment patterns and associated outcomes.

To date, several observational studies have reported on sequencing and treatment patterns in patients with EGFRm NSCLC. For example, the retrospective GioTag study (NCT03370770) investigated outcomes in patients with EGFRm NSCLC receiving sequential afatinib and osimertinib in a real-world clinical practice setting. This study found sequencing with afatinib followed by osimertinib was associated with clinical benefit among patients with T790M-acquired resistance, with a median time on treatment of 27.6 months [17]. Per the inclusion criteria, all patients in the GioTag study received 1L afatinib, and second-line (2L) osimertinib after T790M testing [17, 18]. However, it was subsequently reported that at least $30-40 \%$ of patients who received $1 \mathrm{~L}$ afatinib were ineligible for $2 \mathrm{~L}$ osimertinib, as in many cases progression was due to T790M-independent mechanisms [18].

As some patients died during or after $1 \mathrm{~L}$ treatment, they did not have the opportunity to initiate $2 \mathrm{~L}$ treatment; exclusion of patients who died on $1 \mathrm{~L}$ afatinib potentially introduced immortal time bias in the GioTag study [17].

Real-world studies have also reported that many patients with EGFRm NSCLC treated with 1L 1G/2G EGFR-TKI may not receive subsequent therapy after disease progression and many will die; as such, there is a highly variable proportion of patients in the real-world setting who receive 2L osimertinib following 1L EGFR-TKI [19-23]. Despite reimbursement, many patients may not be treated with osimertinib after they are tested for T790M, and some are not tested at all [20, 21, 23].

Therefore, there remains a need to further understand sequencing and treatment patterns in EGFRm NSCLC following $1 \mathrm{G} / 2 \mathrm{G}$ EGFR-TKIs in a real-world setting. Furthermore, the impact of CNS metastases on treatment patterns is poorly characterized.

Through an analysis of US insurance claims data from the MarketScan ${ }^{\circledR}$ Commercial and Medicare Supplemental Databases, this study examined treatment patterns in patients with locally advanced/metastatic NSCLC receiving $1 \mathrm{~L} 1 \mathrm{G} / 2 \mathrm{G}$ EGFR-TKIs between 1 January 2015 and 30 September 2018. The influence of CNS metastases was also assessed.

\section{Patients and Methods}

\subsection{Study Design}

This was a retrospective observational cohort study analyzing patients newly diagnosed with locally advanced/metastatic NSCLC treated with 1L 1G/2G EGFR-TKIs. Given receipt of EGFR-TKIs approved for EGFRm NSCLC, it was presumed that these patients had EGFRm NSCLC. This presumption was made because EGFRm status, including T790M, is not available in US insurance claims databases.

Administrative claims data were extracted from the MarketScan ${ }^{\circledR}$ Commercial and Medicare Supplemental Databases, which contain data for individuals from all US census regions. These databases record inpatient (requiring overnight hospitalization) and outpatient medical claims, and outpatient pharmacy claims of patients with employersponsored primary health insurance or Medicare Supplemental insurance (paid for by an employer). All database records were de-identified and compliant with US patient confidentiality requirements.

The study period was 1 October 2014-30 September 2018. The follow-up period was variable in length from the date of first lung cancer diagnosis (index date) to the earliest of the following: inpatient death, end of continuous enrollment in a healthcare plan (i.e., the end of data availability) or the end of the study period, whichever occurred first.

\subsection{Patients}

Eligible patients ( $\geq 18$ years old) were identified as having at least two non-diagnostic claims (i.e., claims for a professional encounter and not simply a laboratory test or imaging 
claim used to rule out a condition) with an International Classification of Diseases 9th or 10th edition (ICD-9-CM, ICD-10-CM; Online Supplementary Material Table 1) diagnosis code for lung cancer (within 90 days of each other) between 1 January 2015 and 31 March 2018. Patients were required to have at least one claim for receipt of a $1 \mathrm{G} / 2 \mathrm{G}$ EGFR-TKI (erlotinib, gefitinib, or afatinib), on or within 60 days after index date, in addition to at least 3 months of continuous enrollment prior to index date. Patients were excluded if they had a claim with a diagnosis of lung cancer or claim for an EGFR-TKI (erlotinib, gefitinib, afatinib, or osimertinib) within the 3 months prior to index date (to ensure inclusion of newly diagnosed patients), or prior treatment with chemotherapy regimens commonly used in smallcell lung cancer (e.g., cisplatin and etoposide; cisplatin and irinotecan; carboplatin and etoposide; topotecan; and/or cyclophosphamide, doxorubicin, and vincristine) [24] on or within 60 days after index date.

Patients meeting the eligibility criteria were categorized into two mutually exclusive cohorts: the CNS metastases cohort and the no CNS metastases cohort. The presence of CNS metastases was defined as at least one non-diagnostic medical claim with a diagnosis code for secondary malignant neoplasm of the brain or spinal cord, between 30 days before index date until the end of the study period.

\subsection{Objectives and Outcome Measures}

The primary objective was to describe treatment, attrition, and sequencing patterns in patients newly diagnosed with locally advanced/metastatic NSCLC treated with $1 \mathrm{~L} 1 \mathrm{G} / 2 \mathrm{G}$ EGFR-TKIs. A key exploratory objective was to compare treatment and sequencing patterns among patients with or without CNS metastases.

Patient demographics were captured at index date, and clinical characteristics were obtained during the 3 months prior to index date.

Treatment patterns were assessed during the variable-length follow-up period, beginning at index date. Planned treatment pattern measures included: selection and timing of 1L EGFRTKI initiation (1L therapies erlotinib, gefitinib, afatinib, prescribed as the index-TKI); use of $1 \mathrm{~L}$ add-on therapies (treatments used in addition to 1L/index-TKI, initiated within 30 days of treatment initiation, i.e., bevacizumab, carboplatin, pemetrexed, or other chemotherapy); proportion of inpatient death after each line of therapy; proportion of patients with progression after each line of therapy; subsequent treatments received $(2 \mathrm{~L}$ therapies were medication types prescribed after $1 \mathrm{~L}$ progression, i.e., non-index-TKI, chemotherapy, immuneoncology therapy, other medication; later line therapies were $\geq$ third-line (3L) medication types prescribed after $\geq 2 \mathrm{~L}$ discontinuation); and time to discontinuation of treatments.
Time to discontinuation of treatment was measured from treatment initiation to the last day's supply of treatment before a treatment gap (defined as 60 days). If a patient died prior to a full 60-day treatment gap, or while still on treatment, their time to discontinuation was calculated as the time until inpatient death. However, if a patient had a 60-day treatment gap and died after this, their reason for ending a treatment line was recorded as discontinuation of treatment rather than inpatient death. Patients still on therapy at the end of the follow-up period were censored in the analysis. Due to the nature of the data source, patients could disenroll from their healthcare plan. Disenrollment in the healthcare plan was considered informative to the outcome in this scenario (discontinuation of treatment). As such, in order to avoid biased estimates of treatment duration, disenrollment was considered as a discontinuation event in the analysis. In addition, a sensitivity analysis was carried out to measure discontinuation of treatment based on a treatment gap of at least 90 days after last recorded dose of treatment.

\subsection{Statistical Analysis}

Descriptive analyses of demographic and treatment pattern data were conducted. Data were stratified by CNS metastases status; statistical comparisons between cohorts were evaluated using Chi-squared tests for categorical variables and $t$ tests for continuous variables, with significance reported as nominal $p$ values. $p$ values are provided to help interpretation of data, not to make cross-cohort comparisons. Time to event endpoints were described using the Kaplan-Meier method.

\section{Results}

\subsection{Patients}

A total of 578 patients identified from the databases met the eligibility criteria for study inclusion (Fig. 1). Of these, 275 patients (48\%) had CNS metastases recorded at any time during the study period and 303 (52\%) had no CNS metastases recorded between 30 days before index date through the end of study.

Overall, the majority of patients included were female (64\%) and more were identified from the MarketScan ${ }^{\circledR}$ Commercial Database than the Medicare Supplemental Database (60\% vs. $40 \%$ ). Median age was 63 years (range 33-94) at index date. Patient demographics and clinical characteristics were generally similar across the CNS metastases and no CNS metastases cohorts (Table 1), with the exception that patients in the CNS metastases cohort had a median age of 61 years (range 33-91), versus no CNS metastases with a median age of 66 years (33-94). The majority of patients (74\%) had an index date before 2017 (i.e., 2015 or 2016). A 
similar proportion of patients had pre-2017 index dates in the CNS metastases cohort (71\%) as in the no CNS metastases cohort $(77 \%)$.

\subsection{Treatment Patterns}

The median duration of follow-up from the index date was 13.5 months. Treatment patterns, measured from the time of treatment initiation to the end of follow-up, are summarized in Fig. 2.

\subsubsection{First-Line Therapy}

Among the 578 eligible patients, the most frequently prescribed 1L EGFR-TKI was erlotinib $(72 \% ; n=414)$, followed by afatinib $(26 \% ; n=148)$ and gefitinib $(3 \% ; n=16)$.
The proportions of patients receiving erlotinib, afatinib, and gefitinib were similar for the CNS metastases cohort $(n=$ $275)(69 \%, 28 \%$, and $3 \%$, respectively) and no CNS metastases cohort $(n=303)(74 \%, 23 \%$, and 3\%, respectively).

Thirty-five of the 578 patients $(6 \%)$ received an add-on therapy concurrently with 1L EGFR-TKIs; the most common were bevacizumab $(3 \% ; n=17)$ and carboplatin $(2 \%$; $n=12)$.

In total, $47 \%$ of patients $(n=270 / 578)$ discontinued $1 \mathrm{~L}$ EGFR-TKI treatment. The outcomes for the $53 \%$ of patients ( $n=308 / 578$ ) who were not recorded as discontinuing 1L treatment, including 213 patients who ended continuous enrollment in their healthcare plan, are summarized in Fig. 2. The median time to discontinuation of 1L treatment was 8.2 (95\% confidence interval (CI) 6.9, 9.0) months in the CNS metastases cohort and $7.7(95 \%$ CI 6.9, 8.9) months in
Fig. 1 Summary of patient selection. CNS central nervous system, EGFR-TKI epidermal growth factor receptor-tyrosine kinase inhibitor, SCLC small cell lung cancer, SSA US Social Security Administration

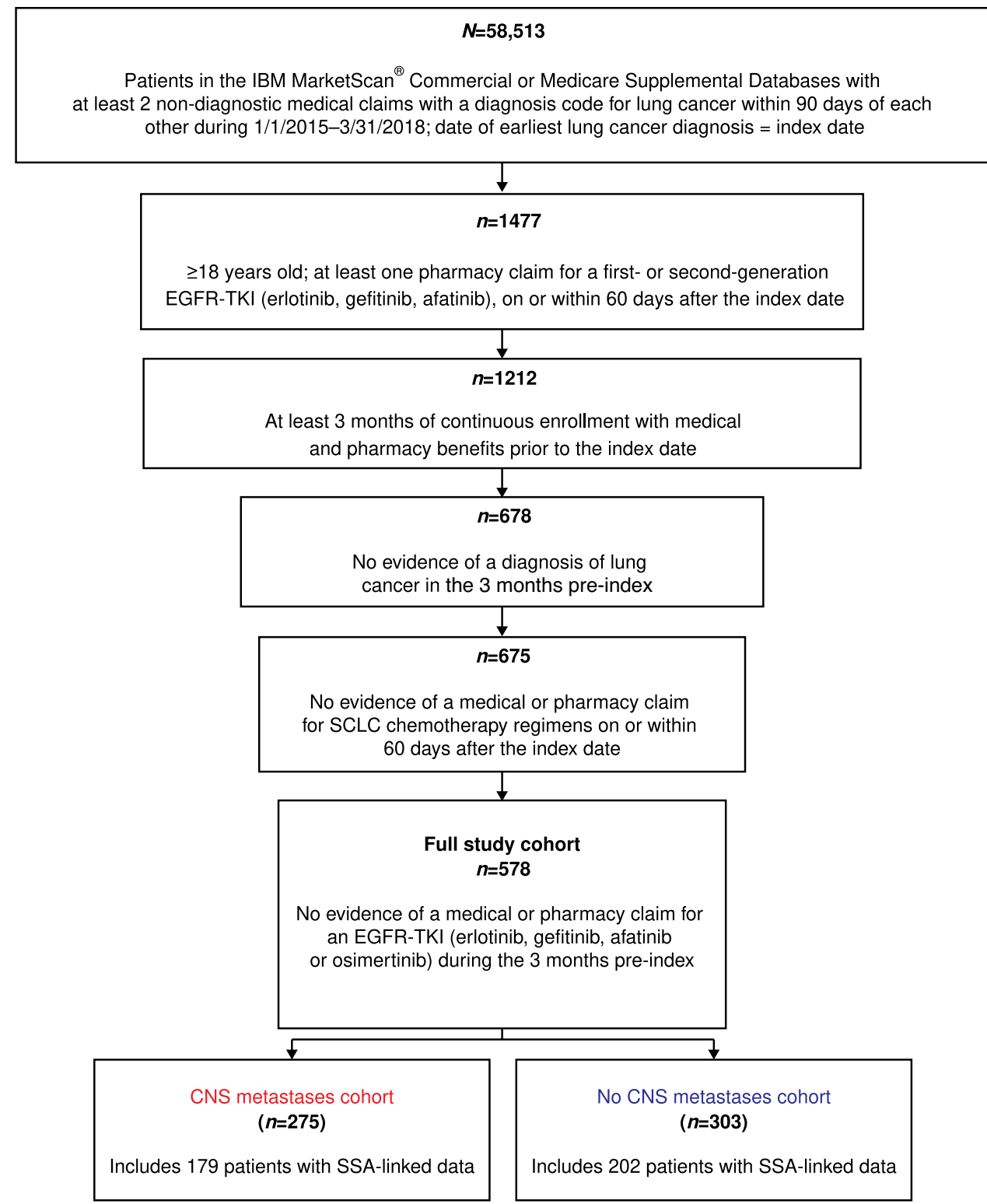


Table 1 Patient characteristics

\begin{tabular}{|c|c|c|c|}
\hline & \multirow[t]{2}{*}{ All patients $(N=578)$} & \multicolumn{2}{|c|}{ CNS metastases status cohorts } \\
\hline & & CNS metastases $(n=275)$ & No CNS metastases $(n=303)$ \\
\hline Sex: male/female, $n(\%)$ & $208(36) / 370(64)$ & $94(34) / 181(66)$ & $114(38) / 189(62)$ \\
\hline Age: median (range), years & $63(33-94)$ & $61(33-91)$ & $66(33-94)$ \\
\hline Payer: commercial/Medicare, $n(\%)$ & $347(60) / 231(40)$ & $204(74) / 71(26)$ & $143(47) / 160(53)$ \\
\hline \multicolumn{4}{|l|}{ Geographic region, $n(\%)$} \\
\hline Northeast & $131(23)$ & $70(25)$ & $61(20)$ \\
\hline North Central & $126(22)$ & $55(20)$ & $71(23)$ \\
\hline South & $203(35)$ & $101(37)$ & $102(34)$ \\
\hline West & $116(20)$ & $49(18)$ & $67(22)$ \\
\hline Unknown & $2(<1)$ & 0 & $2(<1)$ \\
\hline \multicolumn{4}{|l|}{ Index year, $n(\%)$} \\
\hline 2015 & $230(40)$ & $104(38)$ & $126(42)$ \\
\hline 2016 & $196(34)$ & $90(33)$ & $106(35)$ \\
\hline 2017 & $138(24)$ & $73(27)$ & $65(21)$ \\
\hline 2018 & $14(2)$ & $8(3)$ & $6(2)$ \\
\hline Charlson Comorbidity Index, mean (SD) & $2.8(3.4)$ & $3.2(3.7)$ & $2.3(3.0)$ \\
\hline $\begin{array}{l}\text { NCI-adapted Charlson Comorbidity Index, } \\
\text { mean (SD) }\end{array}$ & $0.5(1.0)$ & $0.5(0.9)$ & $0.6(1.1)$ \\
\hline \multicolumn{4}{|l|}{ NSCLC-related symptoms, $n(\%)^{\mathrm{a}}$} \\
\hline Cough & $169(29)$ & $68(25)$ & $101(33)$ \\
\hline Shortness of breath & $90(16)$ & $33(12)$ & $57(19)$ \\
\hline Headaches & $38(7)$ & $29(11)$ & $9(3)$ \\
\hline Fatigue & $37(6)$ & $20(7)$ & $17(6)$ \\
\hline Stroke/transient ischemic attack & $24(4)$ & $9(3)$ & $15(5)$ \\
\hline Depression & $24(4)$ & $14(5)$ & $10(3)$ \\
\hline Anxiety & $21(4)$ & $15(5)$ & $6(2)$ \\
\hline
\end{tabular}

Demographic characteristics were collected on the index date

Clinical characteristics were collected during the 3-month pre-index period

CNS central nervous system, $N C I$ National Cancer Institute, $N S C L C$ non-small-cell lung cancer, $S D$ standard deviation

${ }^{\mathrm{a}} \geq 5 \%$ in either patient cohort

the no CNS metastases cohort (Fig. 3). A sensitivity analysis with discontinuation of treatment based on a treatment gap of at least 90 days after last recorded dose of treatment did not change these results: median time to $1 \mathrm{~L}$ treatment discontinuation was 7.9 months in the CNS metastases cohort and 7.7 months in the no CNS metastases cohort. A greater proportion of patients in the CNS metastases cohort discontinued 1L treatment $(54 \% ; n=149 / 275)$ versus the no CNS metastases cohort (40\%; $n=121 / 303$; nominal $p<0.001)$.

\subsubsection{Second-Line Therapy}

Of the 270 patients who discontinued 1L EGFR-TKI treatment, 77\% ( $n=209 / 270$ ) initiated 2L therapy. Twentythree percent of patients $(n=61 / 270)$ had no claims for subsequent anti-cancer therapies between discontinuation date and end of follow-up. A significantly greater proportion of patients in the CNS metastases cohort (45\%; $n=124 / 275)$ initiated $2 \mathrm{~L}$ therapy than in the no CNS metastases cohort (28\%; $n=85 / 303 ; p<0.001)$.

Of the 209 patients who initiated $2 \mathrm{~L}$ therapy, the most frequently received therapy was osimertinib $(46 \% ; n=96 / 209)$. As a proportion of all patients receiving 1L EGFR-TKIs, $17 \%(n=96 / 578)$ received $2 \mathrm{~L}$ osimertinib. A higher proportion of patients who received $2 \mathrm{~L}$ therapy in the CNS metastases cohort received osimertinib $(52 \% ; n=64 / 124)$ versus the no CNS metastases cohort (38\%; $n=32 / 85 ; p=0.047)$.

In total, $40 \%$ of patients $(n=84 / 209)$ discontinued $2 \mathrm{~L}$ therapy, and the outcomes for the $60 \%$ of patients $(n=$ $125 / 209$ ) who were not recorded as discontinuing their $2 \mathrm{~L}$ therapy are summarized in Fig. 2. 
Fig. 2 Summary of treatment patterns. Treatment patterns were assessed during the variable-length follow-up period. EGFR mutation status was inferred from receipt of EGFR-TKIs; data on EGFR T790M mutation status were not collected. CNS central nervous system, EGFR-TKI epidermal growth factor receptor-tyrosine kinase inhibitor, NSCLC non-small-cell lung cancer. *Deaths detected from claims of inpatient death. ${ }^{\dagger}$ Between discontinuation date and end of patient follow-up. ${ }^{*}$ Targeted therapy cancer medications

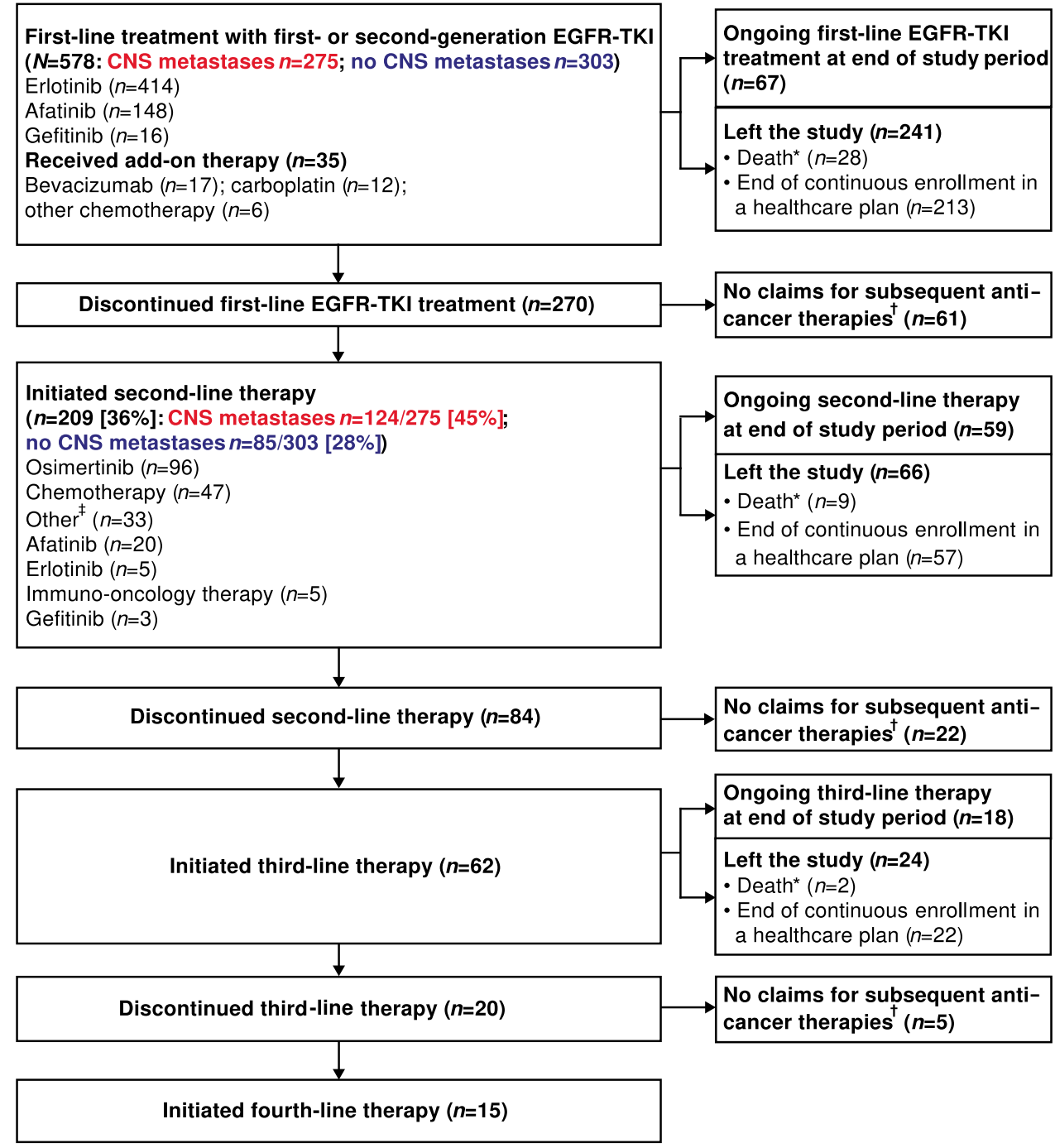

\subsubsection{Later Lines of Therapy}

Of the 84 patients who discontinued 2L therapy, $74 \%$ ( $n$ $=62 / 84)$ initiated 3L. Twenty-six percent of patients $(n=$ 22/84) had no claims for subsequent anti-cancer therapies between discontinuation date and end of follow-up. A higher proportion of patients in the CNS metastases cohort initiated $3 \mathrm{~L}$ therapy $(14 \% ; n=38 / 275)$ than in the no CNS metastases cohort $(8 \% ; n=24 / 303 ; p=0.022)$. Of the full study population, $3 \%$ of patients $(n=15 / 578)$ were recorded as receiving fourth-line therapy (Fig. 2).

\section{Discussion}

This retrospective insurance claims-based analysis provided real-world data on treatment patterns for patients with NSCLC who received 1L 1G/2G EGFR-TKIs. Almost half $(47 \%)$ of patients discontinued $1 \mathrm{~L} 1 \mathrm{G} / 2 \mathrm{G}$ EGFR-TKI treatment and, of the patients who discontinued 1L, 23\% did not initiate $2 \mathrm{~L}$ therapy. In line with our findings, previous observational studies investigating treatment patterns in patients with EGFRm NSCLC reported that 25-30\% of patients progressing on $1 \mathrm{G} / 2 \mathrm{G}$ EGFR-TKIs do not receive 2L therapy [19-23]. Overall, the proportion of patients receiving subsequent therapy following 1L EGFR-TKIs in the real-world setting is sub-optimal [19-23]. Furthermore, a clinically relevant proportion (15-30\%) of patients die prior to receiving $2 \mathrm{~L}[20,21,23]$. Given that approximately $50 \%$ of patients receiving 1G/2G EGFR-TKIs acquire the T790M resistance mutation, there is a biologically driven limit to the number of patients eligible to receive osimertinib as $2 \mathrm{~L}$ treatment $[10,25]$. Selection of $1 \mathrm{~L}$ treatments that optimize outcomes for patients with EGFRm NSCLC is therefore a crucial consideration.

In this study, most patients (74\%) initiated 1L EGFR-TKI treatment prior to 2017, when osimertinib was only indicated for T790M mutation-positive NSCLC with progression on or 


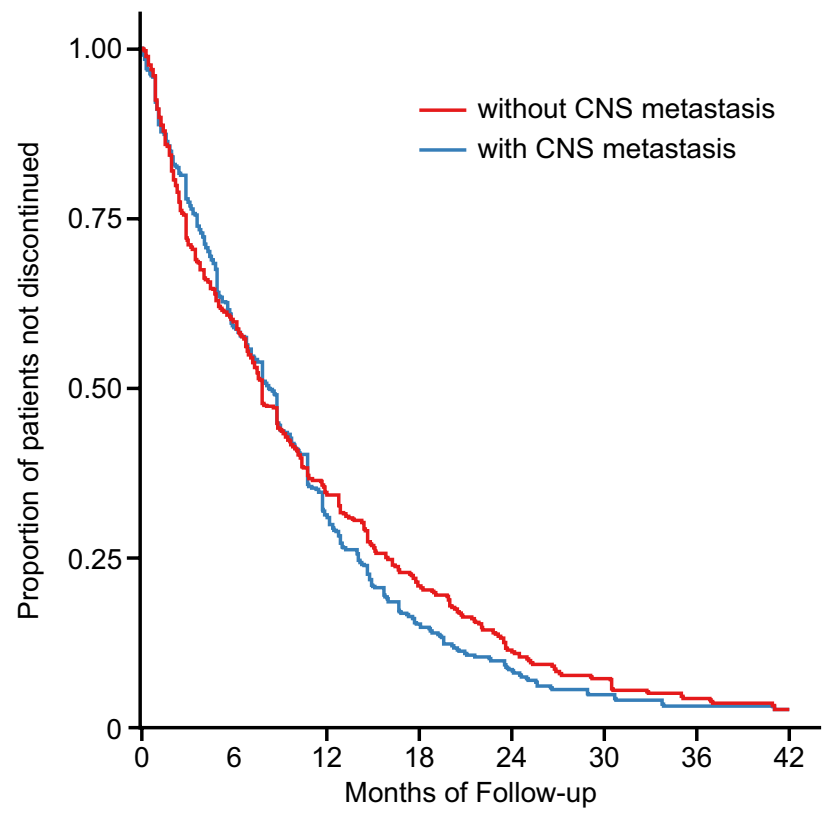

Fig. 3 Median time to treatment discontinuation by months for patients with and without CNS metastases at any time during the study period $(p=0.0016)$. CNS central nervous system

after 1L EGFR-TKI treatment. Osimertinib is now approved, and recommended by current guidelines, as a $1 \mathrm{~L}$ treatment for patients with treatment-naive EGFRm (Ex19del or L858R) metastatic NSCLC, based on the FLAURA study $[13,16]$, but without data for patients receiving $1 \mathrm{~L}$ osimertinib in the present study we are unable to draw conclusions on its real-world benefits. Future studies assessing the real-world effectiveness of $1 \mathrm{~L}$ osimertinib versus $1 \mathrm{~L} 1 \mathrm{G} / 2 \mathrm{G}$ EGFR-TKIs could help to maximize outcomes for patients with EGFRm NSCLC.

The proportion of patients with CNS metastases reported here $(48 \%)$ was higher than expected, but this does include patients with a diagnosis of CNS metastases at any time during the study period; timing of treatments received relative to the development of CNS metastases is not possible in this database. In a previous retrospective study, CNS metastases were reported in up to $39 \%$ of patients with EGFRm NSCLC [26]. However, the sample included 121 patients with EGFRm NSCLC from a Canadian population-based cancer registry where there may have been under-reporting of CNS metastases. Often, registry data can be incomplete as patients are not as rigorously followed as they would be during a clinical study. Therefore, there can be patients who do not present with CNS metastases at diagnosis but develop metastases during the course of their disease, which would not be captured in their records. We also observed that a greater proportion of patients with CNS metastases initiated $2 \mathrm{~L}$ therapy during the study period than those with no CNS metastases, particularly with osimertinib, although it is not known if a patient initiated 2L therapy before or after CNS metastases diagnosis. Osimertinib has been shown to achieve significant exposure in the brain compared with other EGFR-TKIs [27-29]. In a pooled analysis of patients who had progressed following treatment with prior EGFRTKI therapy and who received osimertinib $80 \mathrm{mg}$ once daily, confirmed CNS objective response rate and disease control rate were $54 \%$ and $92 \%$, respectively, demonstrating the clinically meaningful efficacy of osimertinib against CNS metastases in this setting [29]. Osimertinib has also demonstrated efficacy in patients with CNS metastases in the $1 \mathrm{~L}$ setting, including a $52 \%$ reduction in the risk of CNS progression compared with gefitinib or erlotinib $[13,15]$.

A strength of this study was the ability to examine realworld treatment patterns among a relatively large population with advanced/metastatic NSCLC. Through utilizing the MarketScan ${ }^{\circledR}$ Commercial and Medicare Supplemental Databases, this study offered a greater diversity of patients than a claims database from a single health plan or employer. Specifically, use of the MarketScan ${ }^{\circledR}$ Commercial Database meant that a full continuum of care in all inpatient and outpatient settings, as well as retail and specialty pharmacies, was covered. The MarketScan ${ }^{\circledR}$ Commercial and Medicare Supplemental Databases also provide accurate dates of treatment initiation for first and subsequent lines of treatment enabling an accurate examination of the treatment patterns in this patient population.

Despite the advantages of claims-based analyses, several limitations should be noted. In theory, US insurance databases, such as the MarketScan ${ }^{\circledR}$ Commercial and Medicare Supplemental Databases, should provide complete claims histories for patients receiving EGFR-TKIs as they move through the US healthcare system. However, the nature of this analysis and the databases used meant that many patients were lost to follow-up due to end of continuous enrollment in their healthcare plans, and we did not have a complete claims history for all patients. This restricted the duration of time with data available on treatment patterns and sequencing and may have resulted in an underestimation of the proportion of patients initiating $2 \mathrm{~L}$ and subsequent therapy lines during the study. Nevertheless, this highlights the realities experienced by some US patients in clinical practice, for whom loss or disruption of insurance coverage can affect access to care [30-32]. Administrative claims are designed to track healthcare services rendered by providers for administrative purposes associated with reimbursement, rather than for research. Therefore, the presence of diagnoses or medication claims is not definitive evidence of such events and there may be some patient misclassification; in some cases, medications that may have provided further indications of diagnoses might not have been recorded, such as treatments for CNS metastases. Additionally, patients included in this study were limited to those with commercial health coverage 
and private Medicare supplemental coverage as employees, meaning results may not be generalizable to patients with other insurance or those without health-insurance coverage. As the study was limited to US patients, it should be noted that treatment patterns in other countries may differ from those reported here due to differences in patient populations, healthcare systems, and treatment guidelines. Demographic data such as race and ethnicity, which may have affected treatment patterns, were also unavailable.

A further limitation lies in the information captured in insurance claims ICD-9-CM and ICD-10-CM codes. The identification of patients with NSCLC relied on a proximate method due to a lack of NSCLC-specific diagnosis codes in the databases, so misclassification of patients was a possibility. As the date of CNS metastasis was also captured via the insurance claims within a window post-index, these dates may not have been as accurate as from a database that uses health records with specific diagnosis dates, potentially affecting the association between CNS metastases and discontinuation; further analyses using more accurate dates of CNS metastases diagnosis will be needed in order to draw firm conclusions. In addition, all but one patients' CNS metastases were diagnosed post-index. Similarly, EGFRm status is unavailable in insurance claims codes. The study dates were selected in order to understand real-world $2 \mathrm{~L}$ treatment patterns, including osimertinib use, but it was not possible to assess the prevalence of T790M resistance. EGFRm status was therefore inferred from the receipt of EGFR-TKIs. However, it is possible that some patients receiving EGFR-TKIs may have had negative EGFR mutation status and would not have benefited from targeted treatments. In addition, assumptions were made on when patients stopped treatment, as discontinuation dates were not known, meaning that time to treatment discontinuation reported here may be underestimated. The limitations of claims-based analyses may be reflective of real-world challenges in clinical practice, such as treatment decision-making for patients with unavailable T790M mutation status. A final limitation of the study is that afatinib is also used to treat metastatic squamous cell carcinoma in the USA [33], but the role of EGFRm in this histological subtype of NSCLC is debated [34]. Without histology data available in this study, it is possible that some patients who received $1 \mathrm{~L}$ afatinib had squamous histology instead of adenocarcinoma (the latter is well linked to EGFR mutations) [34], creating potential outliers to the population presumed to have EGFRm NSCLC.

\section{Conclusion}

This retrospective real-world analysis of patients identified through US insurance claims databases showed that 270 of 578 patients with NSCLC discontinued 1 L $1 \mathrm{G} / 2 \mathrm{G}$
EGFR-TKIs. Median time to $1 \mathrm{~L}$ treatment discontinuation was 8.2 months in patients diagnosed with CNS metastases and 7.7 months in patients without CNS metastases. Patients with CNS metastases had different treatment patterns, with a greater percentage initiating $2 \mathrm{~L}$ therapy with osimertinib. These results highlight the importance of choosing optimal 1L EGFR-TKI treatment for EGFRm NSCLC, given that not all patients who discontinued 1L 1G/2G EGFR-TKIs initiated $2 \mathrm{~L}$ therapy.

Supplementary Information The online version contains supplementary material available at https://doi.org/10.1007/s40801-021-00272-5.

Acknowledgements Medical writing support for the development of this manuscript, under the direction of the authors, was provided by Sean Mills, BA, and Preeyah Purang, BSc, of Ashfield MedComms, and Ashfield Health company, and funded by AstraZeneca in accordance with Good Publications Practice (GPP3) guidelines (http://www. ismpp.org/gpp3).

\section{Declarations}

Funding This work was supported by AstraZeneca, the manufacturer of osimertinib.

Conflict of interest R. A. Soo declares grants and personal fees from AstraZeneca and Boehringer Ingelheim; personal fees from Amgen, Bristol Myers Squibb, Lilly, Merck, Novartis, Pfizer, Puma Biotechnology, Roche, Taiho, Takeda, and Yuhan; T. Seto declares grants, personal fees, and honoraria from AstraZeneca, Chugai Pharmaceutical, Daiichi Sankyo, Eli Lilly Japan, MSD, Nippon Boehringer Ingelheim, Novartis Pharma, Pfizer Japan, and Takeda Pharmaceutical; personal fees and honoraria from Astellas Pharma, Bristol Myers Squibb, Kyowa Hakko Kirin, Ono Pharmaceutical, Taiho Pharmaceutical, Thermo Fisher Scientific; and grants from AbbVie, Bayer Yakuhin, Kissei Pharmaceutical, LOXO Oncology, and Merck Serono. T. Seto also reports employment for Precision Medicine Asia Co. Ltd.; J.E. Gray declares grants, personal fees and non-financial support from AstraZeneca and Genentech, personal fees and non-financial support from Takeda, grant and personal fees from Bristol Myers Squibb; grants from Boehringer Ingelheim, Array, Merck and personal fees from EMD Serono Merck; E. Thiel declares funding from AstraZeneca (AstraZeneca paid funds to IBM Watson Health to conduct this analysis), personal fees and employment from IBM Watson Health; A. Taylor declares employment and shares with AstraZeneca; W. Sawyer and P. Karimi declare employment for AstraZeneca; E. Marchlewicz declares AstraZeneca contracted IBM Watson Health to provide consulting and data analysis services for this study; M. Brouillette declares employment with IBM Watson Health.

Availability of data Data underlying the findings described in this article may be obtained in accordance with AstraZeneca's data-sharing policy described at: https://astrazenecagrouptrials.pharmacm.com/ST/ Submission/Disclosure.

Code availability Not applicable.

Author contributions Takashi Seto, Jhanelle E. Gray, Ellen Thiel, Aliki Taylor, William Sawyer, Parisa Karimi, Elizabeth Marchlewicz and Matthew Brouillette all substantially contributed to the acquisition, analysis, or interpretation of data for the work. Takashi Seto, Jhanelle E. Gray, Ellen Thiel and Elizabeth Marchlewicz substantially 
contributed to the conception or design of the work as well as project administration. Ross Soo, Takashi Seto, Jhanelle E. Gray, Ellen Thiel, Aliki Taylor, William Sawyer, Parisa Karimi, Elizabeth Marchlewicz and Matthew Brouillette contributed to writing - review and editing as well as writing - original draft of this work. Ellen Thiel, Aliki Taylor, William Sawyer, Parisa Karimi, Elizabeth Marchlewicz and Matthew Brouillette and contributed to the formal analysis. Jhanelle E. Gray, Ellen Thiel and Elizabeth Marchlewicz contributed to the conceptualization and investigation of the work. Ellen Thiel and Elizabeth Marchlewicz contributed to the resources and data curation for the work. Takashi Seto, Jhanelle E. Gray, Ellen Thiel, Aliki Taylor, William Sawyer and Elizabeth Marchlewicz contributed to the methodology. Ross Soo, Jhanelle E. Gray, Ellen Thiel and Elizabeth Marchlewicz contributed to the supervision of the work. William Sawyer contributed to the validation of the work.

Ethics approvals The study was performed in accordance with ethical principles consistent with the Declaration of Helsinki, ICH GCPs, GPP and the applicable legislation on Non-Interventional Studies and/or Observational Studies. The Investigators performed the Observational Study in accordance with the regulations and guidelines governing medical practice and ethics in the country of the Observational Study and in accordance with currently acceptable techniques and knowhow. This study did not require review and approval by ethics committees or informed consent. All IBM Watson Health MarketScan ${ }^{\circledR}$ Commercial and Medicare Database records are de-identified and fully compliant with US patient confidentiality requirements, including the Health Insurance Portability and Accountability Act (HIPAA) of 1996. Because this study used only de-identified patient records and did not involve the collection, use, or transmittal of individually identifiable data, Institutional Review Board approval to conduct this study was not necessary.

Consent to participate Not applicable.

Consent for publication Not applicable.

Open Access This article is licensed under a Creative Commons Attribution-NonCommercial 4.0 International License, which permits any non-commercial use, sharing, adaptation, distribution and reproduction in any medium or format, as long as you give appropriate credit to the original author(s) and the source, provide a link to the Creative Commons licence, and indicate if changes were made. The images or other third party material in this article are included in the article's Creative Commons licence, unless indicated otherwise in a credit line to the material. If material is not included in the article's Creative Commons licence and your intended use is not permitted by statutory regulation or exceeds the permitted use, you will need to obtain permission directly from the copyright holder. To view a copy of this licence, visit http://creativecommons.org/licenses/by-nc/4.0/.

\section{References}

1. Planchard D, Popat S, Kerr K, Novello S, Smit EF, Faivre-Finn C, Mok TS, Reck M, Van Schil PE, Hellmann MD, Peters S. Correction to: "Metastatic non-small cell lung cancer: ESMO Clinical Practice Guidelines for diagnosis, treatment and follow-up." Ann Oncol. 2019;30(5):863-70. https://doi.org/10.1093/annonc/ mdy474.

2. Midha A, Dearden S, McCormack R. EGFR mutation incidence in non-small-cell lung cancer of adenocarcinoma histology: a systematic review and global map by ethnicity (mutMapII). Am J Cancer Res. 2015;5(9):2892-911.

3. Zhang YL, Yuan JQ, Wang KF, Fu XH, Han XR, Threapleton D, Yang ZY, Mao C, Tang JL. The prevalence of EGFR mutation in patients with non-small cell lung cancer: a systematic review and meta-analysis. Oncotarget. 2016;7(48):78985-93. https://doi.org/ 10.18632/oncotarget.12587.

4. Guerin A, Sasane M, Dea K, Zhang J, Culver K, Nitulescu R, Wu EQ, Macalalad AR. The economic burden of brain metastasis among lung cancer patients in the United States. J Med Econ. 2016;19(5):526-36. https://doi.org/10.3111/13696998.2016. 1138962.

5. Fernandes AW, Wu B, Turner RM. Brain metastases in non-small cell lung cancer patients on epidermal growth factor receptor tyrosine kinase inhibitors: symptom and economic burden. J Med Econ. 2017;20(11):1136-47. https://doi.org/10.1080/13696998. 2017.1361960.

6. Ge M, Zhuang Y, Zhou X, Huang R, Liang X, Zhan Q. High probability and frequency of EGFR mutations in non-small cell lung cancer with brain metastases. J Neurooncol. 2017;135(2):413-8. https://doi.org/10.1007/s11060-017-2590-x.

7. Hanna N, Johnson D, Temin S, Baker S Jr, Brahmer J, Ellis PM, Giaccone G, Hesketh PJ, Jaiyesimi I, Leighl NB, Riely GJ, Schiller JH, Schneider BJ, Smith TJ, Tashbar J, Biermann WA, Masters G. Systemic therapy for stage IV non-small-cell lung cancer: American Society of Clinical Oncology Clinical Practice Guideline update. J Clin Oncol. 2017;35(30):3484-515. https://doi.org/ 10.1200/jco.2017.74.6065.

8. Oxnard GR, Arcila ME, Chmielecki J, Ladanyi M, Miller VA, Pao W. New strategies in overcoming acquired resistance to epidermal growth factor receptor tyrosine kinase inhibitors in lung cancer. Clin Cancer Res. 2011;17(17):5530-7. https://doi.org/10.1158/ 1078-0432.ccr-10-2571.

9. Yu HA, Arcila ME, Rekhtman N, Sima CS, Zakowski MF, Pao W, Kris MG, Miller VA, Ladanyi M, Riely GJ. Analysis of tumor specimens at the time of acquired resistance to EGFR-TKI therapy in 155 patients with EGFR-mutant lung cancers. Clin Cancer Res. 2013;19(8):2240-7. https://doi.org/10.1158/1078-0432. CCR-12-2246.

10. Wang Z-F, Ren S-X, Li W, Gao G-H. Frequency of the acquired resistant mutation T790 $\mathrm{M}$ in non-small cell lung cancer patients with active exon 19Del and exon 21 L858R: a systematic review and meta-analysis. BMC Cancer. 2018;18(1):148. https://doi.org/ 10.1186/s12885-018-4075-5.

11. Cross DA, Ashton SE, Ghiorghiu S, Eberlein C, Nebhan CA, Spitzler PJ, Orme JP, Finlay MR, Ward RA, Mellor MJ, Hughes G, Rahi A, Jacobs VN, Red Brewer M, Ichihara E, Sun J, Jin H, Ballard P, Al-Kadhimi K, Rowlinson R, Klinowska T, Richmond GH, Cantarini M, Kim DW, Ranson MR, Pao W. AZD9291, an irreversible EGFR TKI, overcomes T790M-mediated resistance to EGFR inhibitors in lung cancer. Cancer Discov. 2014;4(9):104661. https://doi.org/10.1158/2159-8290.CD-14-0337.

12. Mok TS, Wu Y-L, Ahn M-J, Garassino MC, Kim HR, Ramalingam SS, Shepherd FA, He Y, Akamatsu H, Theelen WSME, Lee CK, Sebastian M, Templeton A, Mann H, Marotti M, Ghiorghiu S, Papadimitrakopoulou VA. Osimertinib or platinum-pemetrexed in EGFR T790M-positive lung cancer. N Engl J Med. 2017;376(7):629-40. https://doi.org/10.1056/NEJMoa1612674.

13. Soria JC, Ohe Y, Vansteenkiste J, Reungwetwattana T, Chewaskulyong B, Lee KH, Dechaphunkul A, Imamura F, Nogami N, Kurata T, Okamoto I, Zhou C, Cho BC, Cheng Y, Cho EK, Voon PJ, Planchard D, Su WC, Gray JE, Lee SM, Hodge R, Marotti M, Rukazenkov Y, Ramalingam SS. Osimertinib in untreated EGFR-mutated advanced non-small-cell lung cancer. N Engl J Med. 2018;378(2):113-25. https://doi.org/10.1056/NEJMoa1713 137. 
14. Wu YL, Ahn MJ, Garassino MC, Han JY, Katakami N, Kim HR, Hodge R, Kaur P, Brown AP, Ghiorghiu D, Papadimitrakopoulou VA, Mok TSK. CNS efficacy of osimertinib in patients with T790M-positive advanced non-small-cell lung cancer: data from a randomized phase III trial (AURA3). J Clin Oncol. 2018;36(26):2702-9. https://doi.org/10.1200/jco.2018.77.9363.

15. Reungwetwattana T, Nakagawa K, Cho BC, Cobo M, Cho EK, Bertolini A, Bohnet S, Zhou C, Lee KH, Nogami N, Okamoto I, Leighl N, Hodge R, McKeown A, Brown AP, Rukazenkov Y, Ramalingam SS, Vansteenkiste J. CNS response to osimertinib versus standard epidermal growth factor receptor tyrosine kinase inhibitors in patients with untreated EGFR-mutated advanced non-small-cell lung cancer. J Clin Oncol. 2018;36(33):3290-7. https://doi.org/10.1200/jco.2018.78.3118.

16. Ramalingam SS, Vansteenkiste J, Planchard D, Cho BC, Gray JE, Ohe Y, Zhou C, Reungwetwattana T, Cheng Y, Chewaskulyong B, Shah R, Cobo M, Lee KH, Cheema P, Tiseo M, John T, Lin MC, Imamura F, Kurata T, Todd A, Hodge R, Saggese M, Rukazenkov Y, Soria JC. Overall survival with osimertinib in untreated, EGFR-mutated advanced NSCLC. N Engl J Med. 2020;382(1):41-50. https://doi.org/10.1056/NEJMoa1913662.

17. Hochmair MJ, Morabito A, Hao D, Yang CT, Soo RA, Yang JC, Gucalp R, Halmos B, Wang L, Golembesky A, Marten A, Cufer T. Sequential treatment with afatinib and osimertinib in patients with EGFR mutation-positive non-small-cell lung cancer: an observational study. Future Oncol. 2018;14(27):2861-74. https://doi.org/ 10.2217/fon-2018-0711.

18. Hochmair MJ, Morabito A, Hao D, Yang C-T, Soo RA, Yang JC-H, Gucalp R, Halmos B, Wang L, Märten A, Cufer T. Sequential afatinib and osimertinib in patients with EGFR mutation-positive non-small-cell lung cancer: updated analysis of the observational GioTag study. Future Oncol. 2019;15(25):2905-14. https:// doi.org/10.2217/fon-2019-0346.

19. Reckamp K, Nieva J, Taylor A, Thakrar B, Wong J, Potter D, Bakker N, Rubinstein W, Sun PJ. P1.01-105 US real-world management of EGFR-mutated advanced NSCLC: prescribing and attrition data from first-to-second-line treatment. J Thorac Oncol. 2019;14(10):S402. https://doi.org/10.1016/j.jtho.2019.08.820.

20. Shah R, Girard N, Nagar SP, Griesinger F, Roeper J, Davis K, Bakker N, Thakrar B, Taylor A, Feliciano J. 1522P Real-world (RW) treatment patterns and outcomes for second-line (2L) therapy and beyond in patients (pts) with epidermal growth factor receptor-mutated (EGFRm) advanced NSCLC receiving a firstline (1L) first- or second-generation $(1 \mathrm{G} / 2 \mathrm{G})$ EGFR tyrosine kinase inhibitor (TKI). Ann Oncol. 2019;30:v624-5. https://doi. org/10.1093/annonc/mdz260.044.

21. Nadler E, Pavilack M, Espirito JL, Clark J, Fernandes A. Observational study of treatment patterns in patients with epidermal growth factor receptor (EGFR) mutation-positive nonsmall cell lung cancer after first-line EGFR-tyrosine kinase inhibitors. Adv Ther. 2020;37:946-54. https://doi.org/10.1007/ s12325-020-01221-4.

22. Roeper J, Lueers AC, Falk M, Schatz S, Tiemann M, Wesseler C, Wiest GH, Sackmann S, Ukena D, Heukamp L, Griesinger F. Risk of not receiving second-line therapy is high in EGFR mt+ patients: real-world data of certified lung cancer centers on treatment sequence in EGFR mt+ patients. Ann Oncol. 2019;30(suppl 2):ii38-68. https://doi.org/10.1016/j.jtho.2018.08.638.

23. Chiang AC, Fernandes AW, Pavilack M, Wu JW, Laliberte F, Duh MS, Chehab N, Subramanian J. EGFR mutation testing and treatment decisions in patients progressing on first- or secondgeneration epidermal growth factor receptor tyrosine kinase inhibitors. BMC Cancer. 2020;20(1):356. https://doi.org/10.1186/ s12885-020-06826-0.

24. Duh MS, Reynolds Weiner J, Lefebvre P, Neary M, Skarin AT. Costs associated with intravenous chemotherapy administration in patients with small cell lung cancer: a retrospective claims database analysis. Curr Med Res Opin. 2008;24(4):967-74. https:// doi.org/10.1185/030079908X280464.

25. John T, Akamatsu H, Delmonte A, Su WC, Lee JS, Chang GC, Huang X, Jenkins S, Wu YL. EGFR mutation analysis for prospective patient selection in AURA3 phase III trial of osimertinib versus platinum-pemetrexed in patients with EGFR T790Mpositive advanced non-small-cell lung cancer. Lung Cancer. 2018;126:133-8. https://doi.org/10.1016/j.lungcan.2018.10.027.

26. Hsu F, De Caluwe A, Anderson D, Nichol A, Toriumi T, Ho C. EGFR mutation status on brain metastases from non-small cell lung cancer. Lung Cancer. 2016;96:101-7. https://doi.org/10. 1016/j.lungcan.2016.04.004.

27. Ballard P, Yates JW, Yang Z, Kim DW, Yang JC, Cantarini M, Pickup K, Jordan A, Hickey M, Grist M, Box M, Johnstrom P, Varnas K, Malmquist J, Thress KS, Janne PA, Cross D. Preclinical comparison of osimertinib with other EGFR-TKIs in EGFR-mutant NSCLC brain metastases models, and early evidence of clinical brain metastases activity. Clin Cancer Res. 2016;22(20):5130-40. https://doi.org/10.1158/1078-0432. ccr-16-0399.

28. Colclough N, Ballard PG, Barton P, Chen K, Cross DAE, Finlay MRV, Han L, Janefeldt A, Johnström P, Ward RA, Wrigley GL, Yan Y, Yates JWT, Zhang D, Zhang Z. 64 Preclinical comparison of the blood brain barrier (BBB) permeability of osimertinib (AZD9291) with other irreversible next generation EGFR TKIs. Eur J Cancer. 2016;69(suppl 1):S28. https://doi.org/10.1016/ S0959-8049(16)32664-8.

29. Goss G, Tsai CM, Shepherd FA, Ahn MJ, Bazhenova L, Crino L, de Marinis F, Felip E, Morabito A, Hodge R, Cantarini M, Johnson M, Mitsudomi T, Janne PA, Yang JC. CNS response to osimertinib in patients with T790M-positive advanced NSCLC: pooled data from two phase II trials. Ann Oncol. 2018;29(3):68793. https://doi.org/10.1093/annonc/mdx820.

30. Schoen C, DesRoches C. Uninsured and unstably insured: the importance of continuous insurance coverage. Health Serv Res. 2000;35(1 Pt 2):187-206.

31. Olson LM, Tang SF, Newacheck PW. Children in the United States with discontinuous health insurance coverage. N Engl J Med. 2005;353(4):382-91. https://doi.org/10.1056/NEJMsa043878.

32. Lavarreda SA, Gatchell M, Ponce N, Brown ER, Chia YJ. Switching health insurance and its effects on access to physician services. Med Care. 2008;46(10):1055-63. https://doi.org/10.1097/MLR. $0 \mathrm{~b} 013 \mathrm{e} 318187 \mathrm{~d} 8 \mathrm{db}$.

33. U.S. Food and Drug Administration. GILOTRIF ${ }^{\circledR}$ (afatinib) highlights of prescribing information. 2018. https://www.accessdata. fda.gov/drugsatfda_docs/label/2018/201292s014lbl.pdf. Accessed 18 May 2020.

34. Cheung AH-K, Tong JH-M, Chung L-Y, Chau S-L, Ng CS-H, Wan IYP, To K-F. EGFR mutation exists in squamous cell lung carcinoma. Pathology. 2020;52(3):323-8. https://doi.org/10. 1016/j.pathol.2019.12.003. 


\section{Authors and Affiliations}

\section{Ross A. Soo ${ }^{1}$. Takashi Seto $^{2}$. Jhanelle E. Gray ${ }^{3}$. Ellen Thiel ${ }^{4} \cdot$ Aliki Taylor $^{5} \cdot$ William Sawyer $^{6} \cdot$ Parisa Karimi $^{7}$. Elizabeth Marchlewicz ${ }^{4} \cdot$ Matthew Brouillette $^{4}$}

Takashi Seto

setocruise@gmail.com

Jhanelle E. Gray

jhanelle.gray@moffitt.org

Ellen Thiel

eriehle@us.ibm.com

Aliki Taylor

aliki.taylor@astrazeneca.com

William Sawyer

william.sawyer@astrazeneca.com

Parisa Karimi

parisa.karimi@astrazeneca.com

Elizabeth Marchlewicz

Elizabeth.Marchlewicz@ibm.com

Matthew Brouillette

mbrouill@us.ibm.com
1 Department of Haematology-Oncology, National University Cancer Institute, National University Health System, 1E Kent Ridge Road, NUHS Tower Block Level 7, Singapore 119228, Singapore

2 Department of Thoracic Oncology, NHO Kyushu Cancer Center, 3-1-1 Notame, Minami-ku, Fukuoka 811-1395, Japan

3 Department of Thoracic Oncology, H. Lee Moffitt Cancer Center and Research Institute, Tampa, FL, USA

4 Custom Data Analytics, IBM Watson Health, Cambridge, MA, USA

5 Oncology Business Unit, AstraZeneca, Cambridge, UK

6 Biometrics Oncology, AstraZeneca, Cambridge, UK

7 Oncology Business Unit, AstraZeneca, Gaithersburg, MD, USA 